\title{
Research on the food packaging migration of chemical substances
}

\author{
Gang Liu ${ }^{1, a, *}$ \\ ${ }^{1}$ The school of food engineering, Jilin Engineering normal university, \\ Changchun, 130052, P. R. China \\ aemail:Ig2010919@163.com
}

Keywords: Food packaging, Migration of chemical substances, Safety

\begin{abstract}
Safety and hygienic of food material have become an important aspect of food. Poisonous and harmful chemicals in the food packaging materials research of migration is one of the hot research topics in the field of technology. Firstly, this paper designed a kind of joint motor fruit harvesting robot so as to reduce the pollution problems in the process of food packaging. Secondly, we studied the food packing migration of chemical substances at home and abroad, then giving some suggestions on how to accelerate the research of food packing migration of chemical substances.
\end{abstract}

\section{Introduction}

People's attention to health induced common attention from the international community for food safety. Packaging materials have been found to represent a source of contamination through food packing migration of chemical substances. We should attach great importance to it. Migration refers to the food-contacted packaging materials, which contains chemicals spreading to food, is full of food "special food additives". Potential migration tends to be more significant material is plastics, coating material, ceramics and glass in common food packaging materials. Food safety incidents caused by Packaging materials in the chemical migration has caused the attention of developed countries as early as the 1970s and 80s. The European Union, Japan, the United States and other developed countries invest a considerable amount of money on studying food packing migration of chemical substances and formulate strict rules and regulations on food-contact packaging materials.

After "PVC cling film carcinogenic incident" in 2005, domestic experts attached great importance to food hygiene safety of packaging materials. They have launched research on health and safety of food packaging materials. It makes domestic research in this field presenting a new situation. Such as Xinyan Yu [1] Analysis on food packaging hygiene safety, Xiaohua Wang [2] analyses the hidden trouble in security food packaging containers and materials and put forward control suggestions. Weirong Yao combined foreign literature and introduced the research progress of food packaging of pollutants abroad. At present, the study of food packing migration of chemical substances also get started and have been some research results. The results have enriched our study about food packing migration of chemical substances.

A series of specific of chemicals in food packaging materials under certain conditions of migration research has been carried out by developed countries. It can supplement and deepen the shortage of simulation experiment. Food grade PVC membrane was studied in migration of plasticizer DEHA to soft and hard cheese by Goulas. Banuf.Ozen[3](2001) studied different food processing methods (microwave, ionizing radiation, infrared radiation, ozone treatment, etc.) impacted on the packaging material. Erika Helmroth [4] (2002) studied the use of different migration model to estimate the amount of migration problems. Paleologos [5] (2005) established a contaminated food in propylene amide and butyl dilute amide NP - HPLC method. These studies to a great extent, supplement and perfect the deficiency of the simple simulation test. It makes the research of food packing migration of chemical substances becoming a complete organic whole. 


\section{Mathematical model}

Grey theory was first proposed by Professor Deng Julong, the Huazhong University of Science and Technology's Theory. GM ( $0, \mathrm{~N})$ model prediction flow is shown in Figure 1.

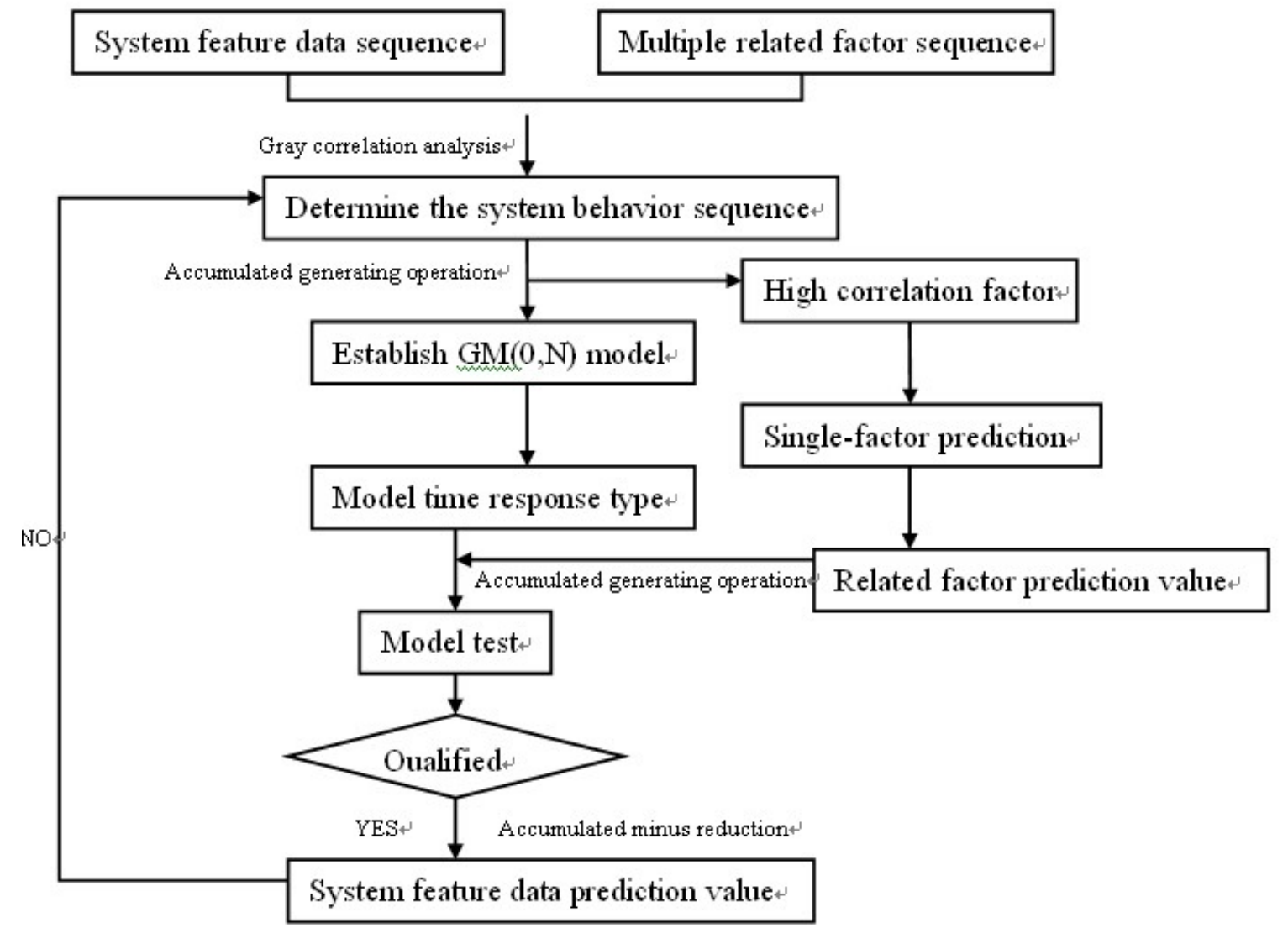

Fig.1 GM $(0, \mathrm{~N})$ model prediction flow

Assume $\quad x_{1}=\left\{x_{1}(1), x_{1}(2), x_{1}(3), \cdots, x_{1}(n)\right\} \quad$ is the dependent variables, $x_{i}=\left\{x_{i}(1), x_{i}(2), x_{i}(3), \cdots, x_{i}(n)\right\}, i=\{1,2,3, \cdots, N\}$ is the independent variables, $x_{i}$ are the time series data.

It is assumed that $x_{i}^{(1)}$ is obtained by $x_{i}^{(0)}$ after AGO. We can get that the predication model of GM $(0, N)$ is like that[21]:

$$
x_{i}^{(1)}(k)=\sum_{i=2}^{N} b_{i} x_{i}^{(i)}(k)+a
$$

In the formula, the parameter, $\hat{b}=\left[b_{2}, b_{3}, \cdots, b_{N}, a\right]$

We can get $\hat{b}$ through the least square method.

$$
\hat{b}=\left(B^{T} B\right)^{-1} B^{T} Y
$$

In the formula,

$$
B=\left[\begin{array}{cccc}
x_{2}^{(1)}(2) & \cdots & x_{N}^{(1)}(2) & 1 \\
\vdots & & & \vdots \\
x_{2}^{(1)}(n) & \cdots & x_{N}^{(1)}(n) & 1
\end{array}\right], \quad Y=\left[\begin{array}{c}
x_{1}^{(1)}(2) \\
x_{1}^{(1)}(3) \\
\vdots \\
x_{1}^{(1)}(n)
\end{array}\right]
$$

The approximate time response formula for solving is: 


$$
x_{i}^{(1)}(k)=\sum_{i=2}^{N} b_{i} x_{i}^{(i)}(k)+a
$$

(4)on the reduction is obtained:

$$
\hat{x}_{1}^{(0)}(k+1)=\hat{x}_{1}^{(1)}(k+1)-\hat{x}_{i}^{(1)}(k), k=1,2,3 \cdots, n-1
$$

In it $\hat{x}_{1}^{(0)}(1)=\hat{x}_{1}^{(1)}(1)$.

\section{Stability analysis}

Define the Lyapunov function is:

$$
V(k)=\frac{1}{2}[S(k)]^{2}
$$

So

$$
\begin{aligned}
& V(k)=\frac{1}{2}[S(k)]^{2} \\
& V(k+1)=\frac{1}{2}[S(k+1)]^{2} \\
& V(k+1)-V(k) \\
& =\frac{1}{2}[S(k+1)]^{2}-\frac{1}{2}[S(k)]^{2} \\
& =\frac{1}{2}\{[S(k+1)-S(k)][S(k+1)+S(k)]\} \\
& V(k)=\frac{1}{2}[S(k)]^{2} \\
& V(k+1)=\frac{1}{2}[S(k+1)]^{2} \\
& \because[S(k+1)+S(k)] \operatorname{sgn}(S(k)) \\
& =\left[-q T S(k)-\frac{|S(k)|}{2} T \tan \operatorname{sig}(\|x\|) \operatorname{sgn}(S(k))\right] \operatorname{sgn}(S(k)) \\
& =-(q+0.5 \tan \operatorname{sig}(\|x\|)) T|S(k)|<0
\end{aligned}
$$

In order to verify the validity of the algorithm, joint servo system of the fruit harvesting robot is studied by numerical simulation using MATLAB, the simulation results shown in Figure 2 and Figure3.

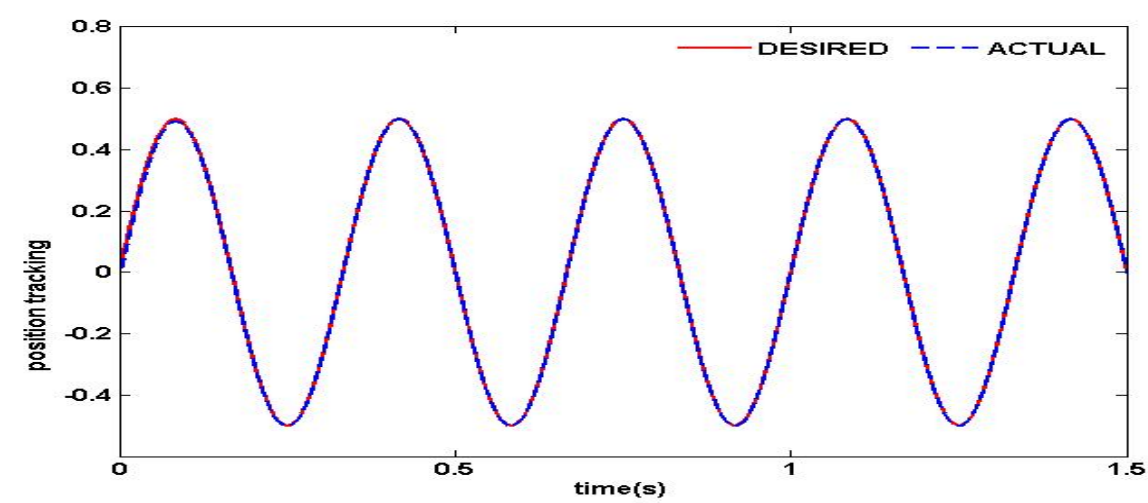

Fig.4 Grey Sliding Mode sliding position tracking 


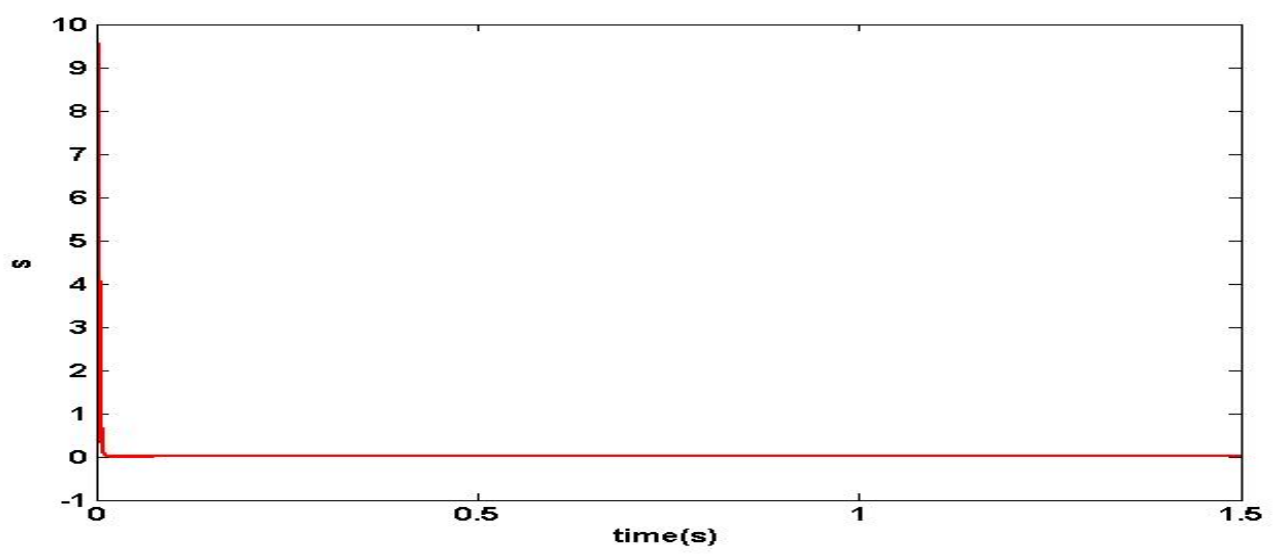

Fig.5 Grey Sliding Mode sliding surface

At present, the study of food packing migration of chemical substances is more comprehensive and thorough in the world. There are some instructions on food packaging and contact materials. They are mainly 89/109 / EEC (general instruction), 84/500 / EEC (ceramic instruction) and 2002 /72 / EEC [1] (plastic instruction). 89/109 / EEC that was passed on December 21, 1989 is about food contact materials of the general regulations. This directive requiring food packaging must be safe. Packaging materials should not change food taste, appearance and cause texture of chemical reactions. Even if the change is good, it can't change the chemical composition of food. The amount of matter migration cannot exceed a certain value. 84/500 / EEC (ceramic instruction) requires the transfer limitation of cadmium and lead in ceramics. The concrete evaluation standard are shown in table 1.

Table 1.The EU ceramic migration of food packaging materials and containers

\begin{tabular}{|c|c|c|}
\hline The container type & $\mathrm{Pb}$ & $\mathrm{Cd}$ \\
\hline $\begin{array}{l}\text { Height is less than } 25 \mathrm{~mm} \\
\text { (Both the container and other) }\end{array}$ & $0.8 \mathrm{mg} / \mathrm{dm}^{2}$ & $0.07 \mathrm{mg} / \mathrm{dm}^{2}$ \\
\hline Other containers & $4.0 \mathrm{mg} / \mathrm{L}$ & $0.3 m g / L$ \\
\hline $\begin{array}{c}\text { Tableware, bigger than 3L } \\
\text { (Packaging or storage containers) }\end{array}$ & $1.5 \mathrm{mg} / \mathrm{L}$ & $0.1 \mathrm{mg} / \mathrm{L}$ \\
\hline
\end{tabular}

\section{Conclusions}

At present, the pollution from food packaging materials has become an important problem that shouldn't be ignored in the field of food safety. We must correctly know the status quo that food packing migration of chemical substances in China. In the refined food classification, development of new solvent, carrying on specific experiments, enhancing great attention, we should put in more manpower and material resources and financial resources to actively improve the current situation, support and encourage research in the field. We can draw lessons from foreign advanced research results to accelerate our research and development process. Only in this way can we avoid becoming the field of dumping poisonous and harmful material of developed countries and occupy the advantage of technology in the future competition. 


\section{References}

[1] X.Y. Yu, Food packaging hygiene safety analysis, Journal of packaging engineering, Vol. 26. No. 5, (2005)43-46.

[2] X.H. Wang, B.C. Zhao, X.Z. Yang, Hidden trouble in security food packaging containers and materials and control, Journal of meat industry, Vol. 7, (2006)35-38.

[3] B.F. Ozen, J.D. Floros, Effects of emerging food processing techniques on packaging materials, Trends in food science and technology, Vol. 12, (2001)60-67.

[4] E. Helmorth, R. Rijk, M. Dekker, W. Jongen, Predictive modeling of migration from packaging materials into food products for regulatory purposes, Food science and technology, Vol. 13 (2002)102-109.

[5] E.K. Paleologos, M.G. Kontominas, Determination of acrylamide and mathacrylamide by normal phase high performance liquid chromatography and UV detection, Journal of chromatography A, Vol.1077(2005)128-135. 